\title{
Different Perspectives of Approaching the Concept of Culture within Politeness Field
}

\author{
Dr. Nisreen Al-Khawaldeh, Ph.D
}

\author{
The Hashemite University/ Jordan; nal-khawaldeh@hu.edu.jo
}

\author{
Doi:10.5901/mjss.2015.v6n6s1p399
}

\begin{abstract}
The notion of culture has received different definitions in pragmatics. Thus, the main purpose of this paper is to critically review and evaluate the current literature on these definitions and the associated approaches followed for studying it within politeness field. It basically considers some significant issues regarding the relationship between these definitions and the integration of the notion of culture and linguistic politeness in the analysis of pragmatic research data. It tries to find out which one of the approaches ( the postmodern and the discursive ) followed for studying the concept of culture should be mainly considered for analyzing the results of cross-cultural studies in terms of cross-cultural differences and politeness. Based on the thematic review conducted on the current literature related to the examination of the definitions of the notion of culture, it can be concluded that these definitions should not be equated rather, they should be made distinguished for pragmatics researchers. The review has shown that drawing upon different perspectives of approaching the concept of culture within politeness field can shed greater light on the analysis and discussion of previous research findings, especially because it is a very essential concept to be considered for the analysis of pragmatic research findings.
\end{abstract}

Keywords: Culture, Politeness, pragmatics, ideology

\section{Introduction}

A critical interpretation of the construct of 'culture' is found essential because numerous 'ideologies' of politeness are often perceived to emanate from particular cultural settings (Bargiela-Chiappini, 2003). Having different beliefs and expectations about what can be a polite linguistic behaviour can be viewed as a specific type of mental metarepresentations, i.e. relating a state or an event to another one based on a causal relationship formerly attested. This means that the more an anticipation is deep-rooted, the stronger it will become(Escandell Vidal, 1998). The link between both states can be viewed conventional such as the case of doing certain type of favour to somebody and expecting to receive certain gratitude expressions.

Sperber's (1996) model of culture as epidemiology of representations offers a suitable framework for elucidating the relationship between individual and social expectations in communication, thus analysing politeness research-based data. Sperber claims that each member of the group has multitude of mental representations, either short-lived or stored in long-term memory. These representations constitute their knowledge and may get communicated, repeated, distributed throughout the same group. This results in a mental account in most of its members.

This indicates that expectations regarding social behaviour are based on socially accepted interpretations (i.e. widely distributed representations) of facts (Escandell Vidal, 1998). Thus, Sperber (1996) views them as higher level (i.e. the general knowledge representations/ expectations) about how lower representations (words and their combinations and other communicative behaviours) that are distributed across a population and used by its members in relation to specific situations under particular conditions. In other words, there are social expectations of the use of specific linguistic expressions that will be considered appropriate in particular contexts. In light of this argument, cultural variations can be viewed as a consequence of the distributions of different representations about the appropriate use of certain linguistic behaviours under particular conditions. Such cultural representations are elucidated in terms of communication between people themselves and other sorts of interaction between people and their milieu (Žegarac, 2008).

Culture needs to be explicitly defined with reference to theoretical work, though it is perceived to be a very difficult notion to define (Scollon and Scollon; 1995; Eelen, 2001; Culpeper, 2011a). Culture has been defined differently by several researchers. Following Sperber (1996), Žegarac (2008) observes that culture can be characterised as a system of representations of a particular type, which he calls cultural representations. A cultural representation is a metarepresentation (i.e. representation of a representation). It is a belief about another mental representation.... which has become wide-spread across a human population on over a significant time-span. On this view, the members of a culture do not necessarily share exactly the same set of cultural representation and the particular representations they hold are 
not identical, but are very similar so that the members of the culture can rely on them in social interaction. In this view, cultures naturally have fuzzy boundaries, and are, in this sense like regions. To give but one example, the phrase 'south Midlands' in the utterance 'Luton is a town in the south Midlands, refers to an area which is identifiable for all practical intents and purposes, although any attempt to draw sharp lines which divide it from the neighbouring regions are illadvised. By the same token, the phrase 'Jordanian culture' or 'English culture' have inherently fuzzy boundaries, but this does not mean that they are not useful concepts. Rather, it means that they are useful to the extent that there are human populations which share an appreciable number of sufficiently similar cultural representations for it to be appropriate to describe them as members of the 'Jordanian culture' or 'English culture'. Whether and to what extent we are justified in using these terms depends on the validity of the generalisations about socio-cultural groups that we are investigating. Žegarac (2008) illustrates how the epidemiological model explains why culture includes a fuzzy set of attitudes, beliefs etc. and examines critically how cultural representations influencing each member of the social group. He compares the impact of epidemic on people to impact of culture on people, i.e. the sharedness and influence occurs to varying degrees.

Žegarac's illustration indicates that a culture cannot exist without some cultural representations being shared in the individuals' minds over a certain period of time to different degrees. Therefore, studying culture cannot be based on studying individual psychology. Similar to the way infections spread in individuals' bodies through interaction between strains of micro-organisms with the same environment they live in, cultural representations spread in people's minds through communicative and other types of, interaction between people and their shared environment (Žegarac, 2008). Given the fact that human populations live in different environments, the culture of a particular group can be viewed as an intricate web of cultural representations pertaining to some themes or regularities than to others (i.e. values, beliefs, principles and orientations to life, perceptions of role relationships comprising rights and obligations related to them, conventions, behavioural rituals and routines, which may involve using language, various norms and conventions of communication, etc.) (Spencer-Oatey, 2005).

This epidemiological perspective on culture is consistent with Matsumoto's (1996) contention that culture is both an individual and a social construct and views it as set of attitudes, values, beliefs, and behaviors shared by certain group of people. It rather differs from one individual to another and from one generation $t$ another . In the same vein, Avruch (1998) points out that culture comprises of the organised, learned or created derivatives of experience including images and their interpretations spread over time. Similarly, Spencer-Oatey (2008) defines culture as a fuzzy set of values behavioural conventions, beliefs, attitudes, assumptions shared by a group of people, and influence their behaviour and interpretations of the behaviour and believes of other people. These conceptualisations of culture mesh well with the epidemiological model of culture as they imply that culture is embedded in a more general epidemiology of individual and social representations and practices. Thus, culture should not be equated to nations because nations are made up of many cultures such as different language groups, ages, genders, geographical communities, and academic disciplines, etc. whose members share and presume that they largely share comparable cultural representations held by most of them (Culpeper, 2011a; Žegarac, 2008). Living in fairly comparable environments and social structures could result in major similarities in the way cultures are formed, but there are still individual differences within the same culture (Spencer-Oatey, 2012). Hofstede's (1994) definition of culture as the collective programming of the mind distinguishable among groups of people suggests that culture could be situated between human nature, which is not programmed, nor programmable and the individual's personality (Dahl, 2004). Hofstede argues that this notion of the culture in the individual is specifically valuable for elucidating culture and allowing for the diversity of individual personalities within each culture (Dahl, 2004).

The aforementioned definitions of culture imply that culture is a combination of variables underlying human behaviour. According to Hofstede (2001), values are the invisible part of culture manifested through cultural practices, consisting of symbols, heroes, and rituals. Values are broad tendencies to favor particular states of affairs over others (Hofstede, 1991) and joint expectations of what comprise appropriate or inappropriate behaviour (Ting-Toomey and Chung, 2005). Hofstede envisages the relationship between culture, values, and practices as the Onion Diagram (2001) claiming that cultural values drive practices. Hofstede (1991) argues that although specific aspects of culture are physically visible, their meaning is invisible and lies specifically and only in the way these practices are understood by the members of the same group. Spencer-Oatey (2012) provides an example of the 'ring gesture' (thumb and forefinger touching) which may be construed as conveying agreement or acceptance in the USA, the UK and Canada and an insult or obscene in several Mediterranean countries. The main difference between Hofstede's approach to culture and Sperber's (1996) epidemiological mode is that central to the former is the notion of 'value' and central to the latter is the notion of '(cultural) representation'. The two models have not been compared so far, but it could be argued that they have different implications for explanation and research. Crucially, the concept of value seems rather general and it could be 
argued that it provides the basis for ex post facto explanations. For example, explanations of the type 'person $X$ behaves in way $Y$, because person $X$ comes from a collectivist culture' seems to rest on the assumption that 'collectivism' (and 'individualism') are essential features which guide and inform behaviour. There is very little evidence to support this view. In fact, it is the behavioural patterns of individuals that provide the basis for generalisations about the type of culture they belong to, but such descriptive generalisations should not be used to explain the very behaviours that they are based on.

\section{Significance of the Study}

This paper is very significant for pragmatists and novel researcher in pragmatics. It shows that it is more promising to investigate descriptively how people behave and how they represent their behaviours, say those relating to politeness, among themselves within populations, and try to establish how their shared representations are manifested in their behaviour. This is consistent with Eelen's approach to politeness. The present author regards culture as a fundamental issue in the field of politeness claiming that politeness varies across cultures based on cultural expectations arising from cultural norms which are reflected in speech acts and differ from one language, regional and social variety to another. These social norms, which are shared by all individuals and pertain to situations and cultures, are the driving force behind the system of politeness (Eelen, 2001). However, Eelen (2001) claims that though culture may be useful being viewed as a conceptual descriptive notion or an a posteriori derivation of the examination of people's behaviour, it cannot per se function as a concrete explanatory concept or as an a priori casual feature for individual behaviour. He opposes the use of culture in traditional theories of politeness as an explanatory notion through notions such as scripts, cultural norms, and rules mainly because this can only explain polite (i.e. 'truly cultural') behaviour. This has led to relegating impoliteness to a phenomenon outside culture and view cultures as internally homogeneous. Considering norms and rules to be explanatory factors for human behaviour indicates that they are ingrained in peoples' mind upon which they rely to determine the way they act themselves and make sense of other people's behaviour, thus they form the basis of social communication (Eelen, 2001). This also indicates that based on the social norms that stipulate what is appropriate for a particular interactional situation, communicative success can evaluated based on the right amount and type of politeness applied at the right time to the right person and the right speech act (Eelen, 2001). This implies that everyday evaluations of politeness in traditional theories are justified and reinforced implicitly or explicitly prior through references to socially shared norms.

\section{Research Objectives and Hypothesis}

The main objective of this paper is to find out which one of the approaches followed for studying the concept of culture should be mainly considered for analyzing the results of cross-cultural studies in terms of cross-cultural differences and politeness. The author hypotheses that the terms of culture should not be considered as a fixed term because it is mainly based on society's norms and values which are continually negotiated and eventually change over time in every type of social interaction.

\section{Methodology}

The author of this paper follows a qualitative methodology called a thematic review of previous literature in order to critically review the definitions of the conception of culture and the associated approaches followed for studying it within politeness field. It provides an in-depth investigation of ideology, procedures, evaluation of the notion of culture. It mainly focuses on culture as a central concept which is taken under consideration from different perspectives in the area of pragmatics. It can be viewed as a comparative study aiming to analyze one particular notion interpreted from different approaches to provide a range of diverse inputs in analyzing pragmatic research data. The main reason for using such evaluative method of two perspectives is that because it provides a better way to recognize the notion of culture based on the literature from two or more approaches. This review paper can be considered a theoretical contribution that provides a value-added contribution to existing ways of thinking, i.e. scholars' existing views of the conception of culture in important ways.

\section{Literature and Theoretical Framework}

Eelen (2001) argues that the theoretical production of cultural norms must be neglected because this view of culture is 
problematic as individuals are unconsciously perceived as cultural dopes that employ specific politeness forms or strategies basically, for example, because they are Chinese or Japanese (Eelen, 2001; Haugh, 2011). Culpeper (2011a) contends that conceptualisation of culture as a relatively shortlist of steady features passed on across generations is erroneous. This is mainly because cultures are various and continually changing, people shift in and out of particular cultures (cf. Kachru, 1999; Gudyunst and Kim, 2003) and discourse shapes culture and is also shaped by it (cf. Gee, 2008). Haugh (2011) maintains that the variability in evaluations of (im)politeness found in empirical studies challenges the supposition that the cultural norms of politeness are homogeneous or even mostly shared among members of particular communities. Nonetheless, very few studies have acknowledged that culture itself changes over time through interaction and if being influenced by another culture (Kim and Gudykunst, 2005; Erez and Gati, 2004). Although cultures share some broad features (i.e. representations), they are dynamic because they constitute a large-scale outcome of people conversing over time (Eelen, 2001), and the individual is a distinctive variation of this shared culture (Parsons, 1966:7). Cultures are not homogeneous because there are different views on what constitutes polite and impolite behaviour within each culture, and no culture will unequivocally hold to certain norms for what constitutes polite or impolite behaviour (Mills and Kádár, 2011). The extent to which the target culture could change depends on the extent to which people are attracted to the other culture and on how deeply they endeavour to maintain their own cultural identity (Berry, 1980). In particular, Locher (2006) argues that politeness is an elusive concept being inherently related to judgements on norms and those are continually negotiated and eventually change over time in every type of social interaction.

Consequently, Culpeper (2011a) claims that impoliteness research should capture the fact that different groups of people or different 'cultures' have diverse norms and values. Norms and values lie at the heart of all social behaviour and in this scope of the present research as Mills, (2009) and Culpeper, (2011a) point out they are central to (im)politeness. Haugh (2003) distinguishes between two types of norms: norms about what one should do, and norms about what one is likely to do or what Terkourafi (2005) terms prescriptive/theoretical versus descriptive/empirical norms. That is, while the rules of traditional theories (e.g. Lakoff and Leech) reiterate conceptualisations of what one should do, Eelen (2001) suggests that norms and culture should be studied as discursive phenomena, that is, as social practices that have their own specific social effects, purposes and motivations, and vary in their associated perceptions, thus they should be perceived as essential components of politeness, not to be explicated by the analyst.

This argument highlights the importance of distinguishing between a bottom-up and top-down approach to the model of culture and in particular (im)politeness. A bottom-up approach to the model of culture depict influences among people and structures interactions. In other words, the interactions among people produce the social practices and understandings through which institutions and ideologies are created (McKinlay, and McVittie, 2008). Therefore such individual phenomena (i.e. a sense of self arise) and societal phenomena (i.e. ideologies) only exist as there are interactions among people through which they are manifested (McKinlay, and McVittie, 2008). On the other hand, the topdown approach suggests that ideological and cultural issues from the societal level restrict the ways in which identities are established and maintained at the interactional level, and the resulted interactional outcomes in turn limit the ways in which one understands oneself at the individual level (McKinlay and McVittie, 2008).

Eelen's distinction between politeness1 and politeness2 is most commonly used to represent a shift in methodology (from 'top-down' theoretical models to 'bottom up' empirical investigations of lay people conceptualisations of social norms (Clark, 2011). Bousfield and Culpeper (2008) point out the traditional approaches are top-down constructs as they advocate a priori intentions which the hearer should just re-discover whereas the discursive approaches (Watts 2003, Mills, 2003; Linguistic Politeness Research Group, 2011) are bottom-up models because they are more inclined to treat intentions as post-facto phenomena. Eelen (2001) illustrates that the scientific concepts of the traditional theories are exact, abstract, pre-defined and detached from everyday life and used for explanation of the empirical content. In other words, the discursive approaches focus on what is considered polite, impolite, or destabilises harmonious communication from the perspectives of the interactants themselves. In particular, they concentrate on spontaneous concepts belonging to everyday reality and experience, therefore their primary acquisitional form is empirical Eelen (2001:33). In this sense, these approaches, following the bottom-up approach, mark a shift from a generic theoretical model of (im)politeness accounting for an 'ideal' participant and emphasise instead the importance of investigating laypersons' practice (experience) and understanding of what is (im)polite and the contextual and intentional aspects to generalisingconceptualisation (Bousfield and Locher, 2008; Culpeper, 2011a). Hence, it could be argued that they are known and recognised in action before they are perceived consciously and conceptually based on completely assimilated empirical content (Eelen, 2001). Watts (2003) argues that the discursive conception of politeness is incompatible with a simple conception of social norms as rules decided upon by others instead of by ourselves. Assuming the normative changing evaluations of polite behaviour made by lay people in interaction, culture in the discursive approach is mainly 
addressed through an examination of variability in interactants' evaluations of politeness across different Communities of Practice and other groups within a specific society (Haugh, 2007). Due to the fact that interactants do not always clearly reveal or discuss evaluations of (im)politeness in interaction, theorists have also examined the implicit and post-hoc evaluations of (im)politeness made by interlocutors (Watts, 2003; Locher, 2004, 2006; Locher and Watts, 2005; Culpeper, 2008; 2011a). This indicates that the bottom-up discursive approach in analysing culture makes the participants the analysts of their own communications, thus make the analysts only represent the participants' interpretations of the interaction (Haugh, 2007). Bottom-up processes characterise phenomena that have established at a lower level originated in the characteristics of individuals such as cognition, behaviour and personal characteristics, but they emerge later as higher-level collective phenomenon through interactions with others (Klein and Kozlowski, 2000). For instance, what constitutes team cognition, behaviour and personal characteristics is originated in the individual elements that compose the team which emerge into a group property through interactions among the same team members (Erez, and Gati, 2004). Individuals in the same team (e.g. individuals who are linked by the workflow) tend to interact with each other more than with others outside their team (e.g. individuals who are only linked indirectly) (Brass, 1995). The characteristics of a particular structural unit (i.e. team) arise over time as a result of dynamic interactions. Haugh (2011) states that one of the main aims of discursive psychology is to analyse "discourse in which mental states become relevant, as a form of social action which is oriented to interactional and inferential concerns" (Wooffitt, 2005: 89), with mental states comprising beliefs, knowledge, memories, attitudes, and motives. Perceiving politeness debatably at its core an interpersonal attitude (Culpeper, 2011b; Haugh, 2007), Haugh (2011) argues that analysing discourse in which politeness is viewed as an attitude becomes related to the participants; hence it is evidently discursive in nature.

On the contrary, the top-down processes shape culture by conveying the influence of higher-level contextual factors (e.g. cultural diffusion) through globalisation, media, shared norms, and then develop into shared values and basic assumptions, etc. on phenomena at lower levels of the system (i.e. practices of the members of the same culture) (Klein and Kozlowski, 2000). In other words, the reality of the members of the culture is not determined by its individual elements but, rather, by the composition of these aforementioned contextual factors. This in turn establishes a new reality at the societal level. Schein (1992) notes that top-down processes may first influence the behaviours and practices of the member of the culture. If social institutions are defined as regulative representations (norms) about how other representation (e.g. words, types of utterances, topics of conversation, etc. are distributed (i.e. displayed or performed) in various types of social situations, then it could be argued that they actually can work top down, i.e. people may behave the way they do because they have learnt or internalised the norms, not just because they take part in the patterns of behaving which they see shared by others. They stipulate norms of behaviour the interlocutors are expected to uphold in the sense that they outline what "types of speech acts can be seen as appropriate" in certain situations (Fraser and Nolen, 1981: 94). Consequently, people develop mental representations that regulate the cultural behaviours relating to (im) politeness or the norms are there from the beginning, so by sharing in the behaviours people actually also accept/learn the norms. Eelen (2001) argues that "politeness is subject to cultural expectations arising from cultural norms, and cultural scripts provide speakers with the means to meet these expectations. The scripts thus become the operational (linguistic-technical) counterpart of the norms: they represent the way norms manifest themselves in actual behaviour". For example, the rules of Ide's notion of discernment reflect the speaker's choice of expressions to conform to the prescribed norms which are out there in the society (prescription). Viewing politeness as being determined by a set of socially shared norms independent of interlocutors means that any speaker behaviour is construed similarly by any hearer within the limit of variable competence. This, from Eelen's perspective, leads to view social reality as not only a unique reality independent of the individual level (Parsons,1971), but also precede over the individual as the latter occupies a lower position (Eelen,2001).

Eelen (2001) claims that the objective approach to social structure is attributed to the Parsonian's top down rather than bottom up view of society and culture. In other words, society is conceptualised as involving a hierarchical structure of behavioural control which Parsons calls a cybernetic hierarchy (Parsons 1966, cited in Eelen 2001: 189). In this structure, the cultural system (values, beliefs, myths, etc.) is at the top of the hierarchy and controls the social system which in turn controls the personality systems in the individual and behavioural systems in social groups. It is in this sense that the social values which are internalised during socialisation are a priori regulative factors determining people's behaviour. Eelen (2001) and Watts (2003) critique the Parosonian perspective, which is viewed as comparable to the traditional approach to politeness, for perceiving persons as powerless playing only a strictly limited role in constructing social reality. Watts (2003) explains that "Parsonian view of society comprises of regularised restriction on regular or suitable social behaviour and sets of institutions that determine the structuring of social groups and the roles which individuals are anticipated to play in those groups. Due to the fact that society determines individuals' behaviour, context and culture could be viewed as predetermined and static and the individuals cannot determine or even influence the rules 
of the social system, or the conceptualisation of (im)politeness (Eelen, 2001).

Drawing on Bourdieu's (1991) notion of habitus, Eelen (2001) claims that a common world should be hypothesised as consisting of a set of beliefs and practices that people accept, share and envisage as their culture, and with which researchers need to engage as individuals. Habitus is a social mechanism that consists of a set of dispositions to act in a manner which is suitable to the social structures objectified by individuals through their experience of social interaction (Watts, 2003) and provide regulated behaviour without positing external regulating force (Eelen, 2001). Bourdieu (1991) describes habitus as the disposition [which] generates practices, perceptions and attitudes which are 'regular' without being consciously co-ordinated or governed by any 'rule'. Thus, politeness can be based on interlocutors' habitus (Eelen, 2001). Eelen strongly rejects prescriptivism, indicating that the emphasis on variability and individual creativity mean that prediction will no longer be potential (2001). However, Eelen acknowledges that there is a consensus in politeness which is illustrated by using the concept of habitus. In other words, people acquire habitus through their experience of social interactions: their previous interaction or their history in Bourdieu's (1991) term and their present interaction which also influences and establishes their habitus (Murata, 2008). Eelen (ibid) although a person's habitus shares a common part with those of other people, it is unique to each individual. Thus, it could be stated that the notable characteristics of Eelen's notion of habitus are variability and individual creativity (Murata, 2008). Though integrating the notion of habitus with the model of communities of practice, Mills (2003) argues that what influences the assessment of appropriateness, which is very related to politeness, is not only the individuals' habitus but also from the communities of practice where they are involved. Nevertheless appropriateness is not imposed on people rather it has to be determined by them assessing their own status compared to other participants in the community of practice (Mills, 2003).

Consequently, the norms can be viewed as the unwritten rules for peoples' behaviour developed through repetition of performing things in certain ways (Watts, 2003; Terkourafi, 2005). However, Mills (2011) argues that interlocutors perceive these shared attitudes or practices as establishing a norm and negotiated with in terms of their perception of what is considered acceptable for their own behaviour. Mills (2011) argues that habitus is flexible system of behaviour , i.e. a way of moving from materialist analysis the significance of exterior factors to the individual in self-construction, towards a more individualistic framework of investigation. However, Eelen contends that politeness is most effectively analysed not as 'a system', but as a social practice which is both dynamic and interactive considering variability as a positive element that builds into human communication a capability for social and cultural negotiation and change rather than as an inconvenience. Watts (2003) claims that researchers in the discursive approach take a more dynamic approach to politeness and place politeness within a theory of social practice, where social should not be understood on the level of society/culture, rather it should be taken as a reference to what goes on between human beings, between individuals, in the production or social reality (Eelen, 2001) and practice is visible in cases of ongoing social interaction between individuals (Watts 2003), and they take a more dynamic approach to politeness then the previous studies. Based on this, Eelen indicates that ideas of politeness are not simply the consequence of a passive learning process in which each individual internalises the societal/cultural politeness system, but are an active expression of social positioning comapred others and the social world in general (Eelen, 2001). Consequently, Eelen (2001) argues that notions such as sharedness, norms, competence, culture and politeness can also be considered as representations of reality rather than as factual references to an objective reality.

The traditional politeness theories merely incorporate a pre-constructed object overlooking its social laws of construction and disguising its social genesis (Bourdieu 1991) and stress that an a priori view of culture where the social level is causally prior to the individual. This in turn results in the unidirectional determination of the individual by the social level (Eelen 2001). In contrast with the focus of the traditional theorists, Eelen (2001) suggests based on Bourdieu's notion of a dynamic bi-directional view of the social-individual through concentrating on the processes of social production instead on the product of these processes. This bi-directional view of the social-individual which helps to describe how past experience mediated present action, creating a new experience that intersects both the meaning and effect of past experiences and future action. This indicates that Bourdieu's notion of habitus is followed as a guide for developing a theoretical framework in which the social-cultural norms are the consequence of human interaction rather than the opposite (Hamza, 2007). Therefore, Haugh (2011) argues that the role that norms play at the individual level can be better understood through investigating the orientations of participants to specific normative positionings that are implied in their evaluations of politeness and impoliteness.

\section{Conclusion}

In light of the previously discussed fact that cultures share some broad features (i.e. representations) which are dynamically constituted as the outcome of people's interaction over time, the present researcher advocates following an 
interactional bottom-up model rather than a top-down constraint model of culture in analysing the data. It can be concluded that analysing the data should be based on the evaluations made by the participants of their interaction instead of social constraints on their freedom of action because their judgments on what counts polite or impolite are constantly negotiated. Therefore, they ultimately change over time across social interaction situations. The participants should be asked about their evaluations and perception of what is polite and impolite regarding communicative behavior and the contextual and social variables that might influence their judgment and perception and in what ways. The data description and analysis should not depend on a theoretical model which includes an explanatory account of culture and the notions of sharedness or normativity. Thus, it is apparent that the present researcher supports Locher and Watts' (2005) argument that we consider it important to take native speaker assessments of politeness seriously and to make them the basis of a discursive, data-driven, bottom-up approach to politeness. The discursive dispute over such terms in instances of social practice should represent the locus of attention for politeness research.

This paper concludes that the combination of discursive psychological thinking with Bourdieuan sociology provides an example of how the social and the individual, the macro and micro, may be integrated into one coherent view of human reality as a spatio-temporally and intersubjectively dynamic process. As such, not only our view of politeness may be enhanced, but the study of politeness may also contribute to a deeper understanding of social reality in general, because it would lead to the examination of fundamental notions such as social norms or the nature of culture and society, and more generally to a contemplation of the processes involved in the day-to-day constitution of the social world by individual human beings, i.e. the processes of everyday life.

\section{References}

Avruch, K. (1998). Culture and Conflict Resolution. Washington DC: United States Institute of Peace Press.

Bargiela-Chiappini, F. (2003). Face and politeness: new (insights) for old (concepts). Journal of Pragmatics, 35(10): 1453-1469.

Berry, J. (1980). Social and cultural change. In Handbook of Cross Cultural Psychology, H. Triandis and R. Brislin (eds.), 211-280. Boston: Allyn and Bacon.

Bourdieu, P. (1991). Language and Symbolic Power.Harvard: Harvard University Press.

Bousfield, D., Locher, M. (2008).Impoliteness in Language. Berlin: Mouton de Gruyter.

Brass, D. (1995).A social network perspective on human resource management. In Research in Personal and Human Resource Management, G. Ferris (eds.), 39-79. Greenwich, CT: JAI Press.

Clark, J. (2011). No, like proper north: Re-drawing boundaries in an emergent community of practice. In Discursive Approaches to Politeness, Linguistic Politeness Research Group (eds.), 109-132. Berlin/Boston: De GruyterMouton.Culpeper, J. (2011a). Impoliteness: Using Language to Cause Offence. Cambridge: Cambridge University Press.

Culpeper, J. (2008). Reflections on impoliteness, relational work and power. In Impoliteness in Language: Studies on its Interplay with Power in Theory and Practice, D. Bousfield, and M. Locher (eds.), 17-44. Berlin: NewYork: Mouton de Gruyter.

Dahl, S. (2004) Intercultural research: the current state of knowledge. Middlesex University Discussion Paper.Retrieved on 17th July 2014 from http://Stephan.dahl.at/intercultural/about_culture.html.

Eelen, G. (2001). A Critique of Politeness Theories. Manchester: St Jerome Press.

Erez, M., and Gati, E. (2004). A dynamic, multi-level model of culture: from the micro level of the individual to the macro level of a global culture. Applied Psychology, 53(4): 583-598.

Escandell Vidal, V. (1998). Politeness: a relevant issue for relevance theory. RevistaAlicantina De EstudiosIngleses, 11: 45-57.

Fraser, B. and Nolen, W. (1981).The association of deference with linguistic form. International Journal of the Sociology of Language, 27: 93-111.

Gee, J. (2008). Social Linguistics and Literacies: Ideology on Discourses (3rd eds.). London/New York: Routledge.

Gudykunst, W. and Kim.Y. (2003).Communicating with Strangers. (4th ed.) Berkshire and New York: McGraw-Hill.

Hamza, A. (2007). Review of A Critique of Politeness Theories, by G. Eelen, (2001). Working papers on the Web.Retrieved on 16th June 2014 from http://extra.shu.ac.uk/wpw/politeness/reviews.htm.

Haugh, M., (2003).A metalinguistic approach to deconstructing the concepts of face and politeness in Chinese, English and Japanese.Journal of Pragmatics, 35(10): 1581-1611.

Haugh, M. (2007). The co-constitution of politeness implicature in conversation.Journal of Pragmatics, 39(1): 84-110.

Haugh, M. (2011). Epilogue: culture and norms in politeness research. In Politeness in East Asia, D. Kádár, S. Mills (eds.), 252-264. Cambridge: Cambridge University Press.

Hofstede, G. (1994). Cultures and Organizations: Software of the Mind. London: Harper Collins Business.

Hofstede, G. (2001). Culture's Consequences: Comparing Values, Behaviors, Institutions and Organizations Across Nations. Thousand Oaks: Sage Publications.

Ide, S. (1982). Japanese sociolinguistics: politeness and women's language. Lingua, 57(2):357-385.

Kachru, Y. (1999). Culture, context, and writing.In Culture in Second Language Teaching and Learning, E. Hinkel (eds.), 75-89. Cambridge: Cambridge University Press.

Kim, Y. and Gudykunst W. (2005).Adapting to a new culture. In Theorizing about Intercultural Communication, W. Gudykunst, (eds.), 
375-400. London: Sage Publications.

Klein, K. and Kozlowski, S. (2000). Multilevel Theory, Research, and Methods in Organizations: Foundations, Extensions and New Directions. San Francisco, CA: Jossey-Bass.

Lakoff, R. (1977). What you can do with words: politeness, pragmatics, and performatives. In Proceedings of The Texas Conference on Performatives, Presuppositions, and Implicatures, A. Rogers, B.Wall, J.P.Murphy (eds). 79-105. Arlington: Center of Applied Linguistics.

Lakoff, R. T. (1979). Stylistic strategies within a grammar of style. Annals of the New York Academy of Sciences, 327(1), 53-78.

Linguistic Politeness Research Group, (2011). Discursive Approaches to Politeness.Berlin/Boston Walter de Gruyter.

Locher, M. (2006). Polite behaviour within relational work: the discursive approach to politeness. Multilingua, 25(3):249-267.

Locher, M. and Watts, R. (2005).Politeness theory and relational work.Journal of Politeness Research, 1(1): 9-33.

Matsumoto, D. (1996) Culture and Psychology. Pacific Grove, CA: Brooks/Cole.

McKinlay, A., and McVittie, C. (2008).Social psychology in the Twenty-First Century. In Social Psychology and Discourse, A. McKinlay and C. McVittie (eds.), 254-273. West Sussex: John Wiley and Sons.

Mills, S. (2003). Gender and Politeness. Cambridge: Cambridge University Press.

Mills, S. (2009). Impoliteness in a cultural context.Journal of Pragmatics, 41(5): 1047-1060.

Mills, S. and Kádár, D. (2011).Politeness and culture. In Politeness in East Asia, D. Kádár and S. Mills (eds.), 21-44. Cambridge: Cambridge University Press.

Murata, K. (2008). Politeness theory: its trend and development. The Ryukoku Journal of Humanities and Sciences, 29(2): 1-13. Parsons, T. (1966). Societies: Evolutionary and Comparative Perspectives. Englewood Cliffs: Prentice Hall.

Parsons, T. (1971). The System of Modern Societies. Englewood Cliffs: PrenticeHall.

Schein, E. (1992). Organizational Culture and Leadership. San Francisco, CA: Jossey-Bass.

Scollon, R. and Scollon, S. (1995). Intercultural Communication: A Discourse Approach. Oxford: Blackwell.

Sperber, D. (1996). Explaining Culture. Oxford: Blackwell.

Spencer-Oatey, H., and Franklin, P. (2009).Intercultural Interaction: A Multidisciplinary Approach to Intercultural Communication. Houndmills Basingstoke: Palgrave Macmillan.

Spencer-Oatey, H. (2005). (Im)politeness, face and perceptions of rapport: unpacking their bases and interrelationships. Journal of Politeness Research 1(1):95-119.

Spencer-Oatey, H. (2012) What is culture? A compilation of quotations.GlobalPAD Core Concepts.Retrieved on 23rd May 2014 from http://go.warwick.ac.uk/globalpadintercultura.

Terkourafi, M. (2005).Beyond the micro-level in politeness research.Journal of Politeness Research, 1(2): 237-263.

Ting-Toomey, S. and Chung, L. (2005). Understanding Intercultural Communication. Los Angeles: Roxbury Publishing Company.

Watts, R. (2003). Politeness. Cambridge: Cambridge University Press.

Žegarac, V. (2008).Culture and communication. In Culturally Speaking: Culture, Communication and Politeness Theory, H. SpencerOatey, (eds.), 48-70. London/ New York: Continuum. 